\title{
A Reflexão como termo-médio entre more geometrico e Dialética
}

Fábio Mascarenhas Nolasco

\section{(2) OpenEdition}

Journals

Edição electrónica

URL: http://journals.openedition.org/ref/276

DOI: $10.4000 /$ ref.276

ISSN: 2258-014X

Editora

EuroPhilosophie Editions

Refêrencia eletrónica

Fábio Mascarenhas Nolasco, "A Reflexão como termo-médio entre more geometrico e Dialética », Revista de Estud(i)os sobre Fichte [Online], 4 | 2012, posto online no dia 01 setembro 2012, consultado o 08 setembro 2020. URL : http://journals.openedition.org/ref/276 ; DOI : https://doi.org/10.4000/ref 276

Este documento foi criado de forma automática no dia 8 setembro 2020

(c) EuroPhilosophie 


\title{
A Reflexão como termo-médio entre more geometrico e Dialética
}

\author{
Fábio Mascarenhas Nolasco
}

\section{Introdução}

1 Gostaríamos aqui de chamar a atenção para um aspecto da crítica de Hegel a Fichte que diz respeito à questão da influência da metodologia matemática no procedimento filosófico. Este lado da questão, se observarmos dois momentos importantes da tentativa de Hegel de apresentar e criticar o pensamento de Fichte, o Differenzschrift (1801) e o Glauben und Wissen (julho de 1803), parece talvez um viés que não aparenta tocar o núcleo da crítica de Hegel a Fichte; mas se observarmos logo as primeiras linhas do Über die wissenschaftliche Behandlungsarten des Naturrechts (novembro de 1803), talvez vejamos que não seriam assim tão marginais os questionamentos sobre como a forma geral da matemática se faz presente nas ciências em geral; o que, na opinião de Hegel, impede à Filosofia a possibilidade de alcançar sua verdade.

2 Esta questão se apresenta de maneira acabada na Ciência da Lógica (WdL) de Hegel. Pode-se dizer que, do primeiro tomo desta obra, a Doutrina do Ser, toda a segunda e terceira partes, referentes às subdivisões Quantidade e Medida, são uma tentativa de apresentação crítica da forma matemática da ciência em geral. A respeito do segundo tomo da referida obra, intitulado a Doutrina da Essência, pode-se dizer que se trata da tentativa final de Hegel de apresentar uma refutação imanente ${ }^{1}$ do ponto de vista da Filosofia da Reflexão da Subjetividade, e, portanto, na opinião de Hegel, do fundamento do sistema filosófico de Fichte. Mas, em nossa opinião, a passagem entre essas duas partes mencionadas da WdL parece ter sido pouco explorada, e com isso parece-nos que pouco se disse sobre o que levaria a crítica à matemática das subdivisões finais da Doutrina do Ser desembocar na crítica à filosofia da reflexão, e portanto na crítica a Fichte, da Doutrina da Essência.

3 Nosso objetivo nesta apresentação, portanto, é trazer à tona algumas observações gerais e introdutórias que possibilitariam apresentar a opinião de que, talvez, a crítica 
de Hegel a Fichte possa ser mais uma vez abordada interessantemente se estivermos atentos a essa questão geral da relação entre método matemático e método filosófico. Com esse objetivo de retomar a crítica de Hegel a Fichte não se pretende, de forma nenhuma, negar a importância dos diversos estudos que, desde a década de 1970, nos permitiram retomar o estudo da filosofia de Fichte contra as críticas nem sempre tão compreensivas de Hegel. Acreditamos que esse trabalho de "libertar" a filosofia de Fichte das críticas de Hegel foi levado a cabo com mérito louvável. A presente apresentação não visa, portanto, de maneira alguma, recolocar a questão do acerto ou do erro da crítica, mas apenas trazer simplesmente à tona um aspecto da crítica ao qual, até onde sabemos, ainda não tenha sido dada a merecida atenção.

4 Para trazer à tona algumas questões a respeito desse aspecto pretensamente pouco observado da crítica de Hegel a Fichte, em um primeiro momento buscaremos indicar algumas questões a respeito da caracterização hegeliana da Reflexão, e sua diferença em relação ao Conceito. Em seguida buscaremos trazer à tona uma possível raiz histórica para essa especificidade da reflexão, relacionando-a ao procedimento matemático do Cálculo Infinitesimal. Em último lugar, buscaremos indicar algumas questões sobre o posicionamento hegeliano frente essa pretensa analogia metodológica entre filosofia e ciências subordinadas levada a cabo por Kant e Fichte. ${ }^{2}$

\title{
Reflexão e Conceito (aparente identificação entre reflexão e conceito)
}

5 Hegel caracteriza, em Glauben und Wissen, o pensamento de Fichte como uma totalização da perspectiva filosófica inaugurada por Kant e levada adiante por Jacobi. Essa ideia de que a filosofia fichteana tenha alcançado uma totalização implicará que a crítica hegeliana não poderia, em tese, advir exteriormente ao pensamento de Fichte. Para tentar observar alguns aspectos do que seria essa crítica imanente, buscaremos observar alguns momentos-chave da Doutrina da Essência. No último parágrafo de sua introdução ao último capítulo desta parta da WdL, no qual aparentemente se encontra algo como um resumo de todo o percurso da Lógica da Reflexão, Hegel diz o seguinte:

\begin{abstract}
A relação em seu conceito imediato é a relação da Substância e dos Acidentes, o desvanecer e vir-a-ser imediato da Aparência absoluta em si mesma. Na medida em que a substância se determina como ser-para-si contra um outro, ou que a relação absoluta é determinada como real, a relação se torna a relação de causalidade. Finalmente, na medida em que essa avança enquanto se relacionando consigo mesma, na ação-recíproca, então com isso a relação absoluta se torna de acordo com as determinações que ela contém, e como posta; essa sua unidade posta em suas determinações, que são postas enquanto o todo ele mesmo e, por isso, postas o mesmo tanto enquanto determinações, é, portanto, o Conceito. ${ }^{3}$
\end{abstract}

6 Fichte inaugurou uma utilização filosófica importante do conceito de Wechselwirkung,. ${ }^{4}$ Essa afirmação não parece inovadora, pois, justamente como nos indica Hegel, a açãorecíproca é o conceito que fundamenta essa absoluta relação de si consigo mesmo característica do Idealismo fichteano; isto é, este conceito parece ser o que fundamenta a tentativa fichteana de radicalização do Idealismo kantiano, na medida em que a coisa em si, o outro do eu, é determinada por Fichte não como coisa, mas como não-eu, pura oposição ao eu que é posta no eu pelo próprio eu. Sob o olhar de Hegel, apesar de lidar com as determinações desta unidade posta pela ação-recíproca, Fichte estabelece-as, entretanto, como determinações-da-reflexão, passíveis apenas de alcance por um 
proceder no limite intuitivo, e não ainda puramente enquanto conceito. Ou seja, Fichte faz todo o movimento contido na argumentação hegeliana que termina a Lógica da Essência, o estabelecimento da ação-recíproca como fundamento da liberdade do sujeito, mas não apresenta isso como um processo do conceito, mas do eu; ou, pelo menos, fundamenta esse conceito a partir de uma reflexão a respeito do $\mathrm{Eu}$. O conceito da ação recíproca é posto como o fundamento da relação absoluta, constituinte da posição idealista, mas esse ato de pôr é um ato reflexivo do Eu que se pretende enquanto a apresentação de um conceito, mas não a apresentação de um conceito que determina algo a respeito da subjetividade.

7 Num outro momento em que os pensamentos de Fichte e Hegel parecem quase se identificar, a última frase da Lógica da Essência, encontramos o seguinte:

Essas três totalidades [universalidade, individualidade e particularidade] são pois uma e mesma reflexão, que enquanto referência negativa consigo se diferencia naquelas duas, mas [se diferencia] enquanto uma diferença completamente translúcida, a saber, na simplicidade determinada ou na simples determinidade, que é sua única e mesma identidade. - Isto é o Conceito, o reino da subjetividade ou da liberdade. (WdL, TW6, p. 240)

8 Não custaria muito comparar essas três totalidades mencionadas por Hegel com os três princípios da Doutrina da Ciência de 1794, e dizer que universalidade, individualidade e particularidade são a forma hegeliana de apresentar de modo transformado, enquanto conceitos, o que, enquanto reflexão, Fichte não podia não apresentar senão enquanto a posição do eu, a sua negação pela confrontação com a finitude simples do eu, e a síntese entre infinito e finito apresentada pela limitação do eu finito pelo eu absoluto. $\mathrm{Na}$ apresentação transformada de Hegel, o resultado de todo o percurso da reflexão, a contragosto da própria reflexão, mostra-se como algo que a suspende; isto é, o resultado da reflexão não poderia mais ser apenas uma reflexão, mas precisa ser uma diferença completamente translúcida frente à própria reflexão, i.e. Conceito ${ }^{5}$. 0 procedimento por reflexão apresenta já praticamente toda a forma exterior da argumentação, e indica corretamente, na opinião de Hegel, o resultado efetivo de todo o processo de pensamento - o reino da subjetividade e da liberdade -, mas toda essa apresentação, na medida em que depende da reflexão e pretende permanecer nela, estará fadada à ininteligibilidade, ao esotérico ${ }^{6}$, e apesar de indicar o reino da subjetividade e da liberdade, indica-o apenas dentro do limite do subjetivo enquanto subjetivo, e não alcança a apresentação verdadeira do subjetivo, isto é, do conceito.

\section{Reflexão, Grandezas Negativas, Negação (raiz matemática da diferença entre reflexão e conceito)}

Esse procedimento da filosofia da reflexão, de acordo com o qual ela alcança, a despeito de suas próprias auto-impostas limitações, elementos concretos da verdade, i.e., a qualidade da reflexão caracterizada por Hegel como sendo a situação em que o saber já está para além dos limites que ele próprio se impõe - esse procedimento de se autoimpor limites radica possivelmente, ao nosso ver, numa apropriação filosófica de um procedimento metodológico desenvolvido primeiramente na matemática. Trata-se da questão das "grandezas negativas", utilizadas com sucesso primariamente por Leibniz e Newton na invenção do Cálculo Infinitesimal, sob a forma dos "infinitamente pequenos" que se opõem às quantidades imediatamente definíveis e permitem 
operacionalizar o cálculo dos limites. As "grandezas negativas" têm, por isso, também aplicação importantíssima para a mecânica newtoniana na análise das forças contrastantes que compõem o movimento, ou o repouso, de um determinado corpo.

Kant - em vista da revolução causada tanto nas matemáticas quanto na física em decorrência da invenção do Cálculo Infinitesimal e da aplicação newtoniana dos princípios de tal cálculo na mecânica - escreve em 1763 um texto pequeno intitulado Tentativa de introduzir o conceito de grandeza negativa na sabedoria em geral ${ }^{7}$. Tal texto, como já diz o título, procura fornecer a passagem da utilização especificamente matemática e física do conceito das grandezas negativas para sua utilização filosófica, ou, visto de outra maneira, busca fornecer um conceito daquilo que talvez pudesse ser visto como a última moda da mais alta ciência de seu tempo. Pensamos talvez não ser exagerado dizer que se poderia observar nisso, na utilização das grandezas negativas, talvez a raiz daquilo que, na Crítica da Razão Pura, Kant irá estabelecer como o fato de a matemática e a física terem alcançado a via correta da ciência, e talvez isso explique sua motivação já antiga em introduzir na filosofia um tal procedimento.

11 Tal como as grandezas infinitamente pequenas, i.e., as grandezas que, no limite, deixam de ser grandezas, ou tal como as forças que, tanto numa situação de repouso ou de movimento uniforme, se anulam e constituem paradoxalmente uma situação determinada do corpo, a coisa-em-si kantiana muito bem poderia ser vista, então, simplesmente como a "grandeza negativa" do fenômeno, trazida à baila, tal como os infinitesimais para a integração, para permitir o estabelecimento do horizonte da experiência possível.

Fichte, ele mesmo, de certa forma confirmaria essa maneira de observar a coisa: “Oposto ao eu absoluto (...) o não-eu é nada, simplesmente; oposto ao eu limitável, ele é uma grandeza negativa." 8

Ou seja, a utilização do não-eu, a coisa-em-si, como aquilo que permite a limitação do eu apenas é possível porque o não-eu não é posto como coisa frente ao eu, mas é posto no eu enquanto oposição, i.e., é utilizado apenas enquanto grandeza negativa (e um nada frente ao eu absoluto), tornando-o limitável, determinável.

14 A utilização desse procedimento, inspirado na metodologia matemática leibnizianonewtoniana, que permite lidar com um certo "outro", posto como que para além do eu, que entretanto não está para além dele, mas nele mesmo porque posto por ele mesmo, tal procedimento é caracterizado por Hegel como sendo a especificidade da reflexão enquanto tal: "O ir-além em Outro é reflexão em si mesma; a negação (...) é seu positivo ir-em-conjunto consigo mesmo". (WdL, TW6, p. 239)

15 A reflexão seria, em termos hegelianos, a verdade da utilização das grandezas negativas. Dito de outra maneira, a reflexão seria a observação da categoria da negação a partir da determinidade da reflexão. Ou ainda, a reflexão seria apenas a roupagem filosófica da negação abstrata presente no procedimento matemático que utiliza as grandezas negativas. Elevar a reflexão ao status de negação em si e trazer com isso a possibilidade de uma "diferença completamente translúcida", isto seria a superação da esfera da essência e o início da Lógica do Conceito.

Sendo assim, a tentativa hegeliana de superação da reflexão também poderia ser vista como uma tentativa de superação definitiva da tentativa kantiano-fichteana de superação meramente reflexiva, e não efetivamente negativa, da metodologia matemática; i.e., a elevação da reflexão ao status de negação efetiva seria a superação 
definitiva da utilização filosófica de procedimentos metodológicos tomados de préstimo às matemáticas, e, para Hegel, a única possibilidade da absoluta liberdade autodeterminante da filosofia perante as outras ciências, tal como encontramos no §7 do Prefácio de 1812 da WdL:

O ponto de vista essencial é que se trata universalmente de um novo conceito de procedimento científico. A Filosofia, na medida em que ela deve ser ciência, não pode mais, como relembrei noutro lugar, pegar emprestado o seu método de uma ciência subordinada, tal como é a Matemática. (WdL, TW5, p. 16)

\section{Intuição Pura, Intuição intelectual, Conceito.}

Observar a coisa por esse ponto de vista nos permite questionar a respeito do tipo de relação entre filosofia e matemática, defendida por Kant, Fichte e Hegel. Com o auxílio do estudo de W. Csech ${ }^{9}$, somos lembrados de que uma das questões centrais da Crítica da Razão Pura é responder: "como a matemática pura é possível? como a ciência da natureza pura é possível?" (B 20). Já isso nos permite observar como a filosofia transcendental pretende elevar-se acima da matemática e da ciência da natureza através de um procedimento reflexivo a respeito dessas ciências, que já as toma como seguramente de posse completa a respeito de seu procedimento e do estabelecimento de seus princípios, e indaga apenas a respeito das estruturas que constituem essa possibilidade: não se pergunta se são possíveis, mas como o são, pois o fato de que já estejam constituídas por si mesmas não é questionado. ${ }^{10}$

18 A filosofia da reflexão, de acordo com essa opinião, não se coloca como um efetivo outro, uma efetiva negação, da matemática, mas, utilizando-nos dos termos de Hegel, tal filosofia seria apenas o outro através do qual a estrutura de pensamento matemático pretende ir-além de si, reflexivamente, mas permanecendo em si mesma. Nas palavras de Csech, "nesse sentido, Fichte não fala de uma suspensão (Aufhebung), mas muito mais de uma penetração (Durchdringung) da facticidade das ciências particulares." 11

Haveria, portanto, uma certa analogia metodológica ${ }^{12}$ entre filosofia e as ciências que já encontraram seu reto caminho, para Kant e Fichte. Essa noção de uma analogia metodológica, de uma universalização por analogia, por reflexão e não por negação, de uma revolução copernicana na filosofia, em nossa opinião poderia ser abordada a partir da comparação entre a intuição intelectual do filósofo e a intuição pura do geômetra, a partir do pensamento de Fichte. A intuição intelectual do filósofo seria, de acordo com a perspectiva que estamos elaborando, apenas a universalização por reflexão da intuição pura do geômetra. Ou seja, aquilo que teria que ocupar a posição de procedimento universal é lançado a tais alturas a partir do solo de sua determinidade particular enquanto procedimento geométrico, e acaba por não perder suas características originárias, seu caráter intuitivo, e não se torna conceito. Na opinião de Hegel, trata-se de uma passagem imediata do particular da intuição pura do geômetra para o universal da intuição intelectual, uma passagem que, porque imediata, não consegue se colocar também como negação e, por isso, mesmo havendo de ser vista como uma tentativa efetiva de universalização, precisa ser observada, no limite, enquanto uma afirmação retroativa do proceder geométrico.

Em nossa opinião, a crítica hegeliana ao procedimento por intuição intelectual se coloca como a última etapa de sua crítica à predeterminação do método filosófico pelo método matemático, e, portanto, como o pressuposto negativo essencial para a 
possibilidade do conceito da dialética especulativa como método da filosofia. Ou seja, na opinião de Hegel, seria apenas a tomada de consciência a respeito da necessidade de uma passagem entre método geométrico e método filosófico que se colocasse como uma passagem efetivamente negativa, efetivamente crítica - efetivamente Aufhebung e não apenas uma Durchdringung -; seria apenas a consciência a esse respeito o que permitiria tornar os resultados da intuição intelectual de Fichte (e também os de Schelling) apresentáveis conceitualmente, e elevar a Filosofia ao status de Ciência. A inconsciência a respeito da relação negativa entre método filosófico e método matemático se coloca, para Hegel, como o último obstáculo para a apresentação completa de si do procedimento dialético especulativo. Portanto, em nossa opinião, a partir dessa tomada de consciência específica é que Hegel pretenderá depurar e apresentar conceitualmente toda a riqueza filosófica presente enquanto "intensidade não-desenvolvida" nas filosofias de Fichte e Schelling, e apresentar, portanto, na WdL, o conceito completo da Dialética enquanto método essencialmente filosófico.

Tomar consciência a esse respeito nos permite observar com maior profundidade a necessidade da sequência entre os capítulos da Quantidade e da Medida, da Doutrina do Ser, e a Doutrina da Essência. Isto é, isso nos permite observar como Hegel determina a Filosofia da Reflexão (Kant, Jacobi, Fichte) como o primeiro momento da crítica à identificação entre filosofia e matemática operante nos pensamentos de Descartes e Spinoza, sob o preceito do more geometrico. Mas a reflexão, na opinião de Hegel, se colocaria como uma tentativa de primeira negação do vínculo dogmático entre filosofia e matemática do séc. XVII, uma negação, como dizemos, que não alcança considerar a si mesma como negação, pois ela mesma radica num procedimento matemático: a utilização das grandezas negativas. A crítica completa desse vínculo entre filosofia e matemática seria apenas possível quando a reflexão, se completando, superasse a si mesma, observando-se como apenas termo-médio dessa passagem entre a medida (Maß) e o Conceito: com o que, portanto, se alcançaria a possibilidade de dar forma inteiramente conceitual para aquilo apenas intuído intelectualmente. Nesse sentido, poderíamos observar o Conceito como o efetivo pôr (setzen) ou o efetivo apresentar (darstellen) da intuição intelectual.

\section{NOTAS}

1. Hegel, na introdução à Lógica Subjetiva (Doutrina do Conceito), tece longos comentários sobre o que constituiria uma crítica imanente, de forma a justificar a asserção de que apenas a respeito da Ciência da Lógica, e especificamente apenas naquele momento do texto, o da passagem entre a Lógica da Reflexão para a do Conceito, se poderia dizer com justiça de que se trata de uma refutação do sistema de Spinoza. Essa asserção de Hegel, e todo o seu esforço em justificá-la, advém de que Fichte ele mesmo já havia dito, na Grundlage de 1794, que a Doutrina da Ciência seria a refutação do espinosismo, tal como Schelling diversas vezes apresentava o seu sistema como a efetiva refutação (ou afirmação completa) de Spinoza. As primeiras páginas da Lógica do Conceito precisavam, assim, apresentar o que seria o conceito hegeliano de uma verdadeira refutação filosófica, justamente porque uma tal refutação havia acabado de ser empreendida na 
Lógica da Reflexão - a tentativa hegeliana de refutação imanente da Filosofia da Reflexão -; e apenas depois de executada alcançar-se-ia então a possibilidade de se apresentar o conceito do que havia sido então feito: trata, portanto, a Lógica do Conceito, de apresentar o que seria a refutação do sistema de Spinoza, isto é dizer que, na opinião de Hegel, apenas o conceito apresenta a refutação a Spinoza, e não a reflexão em si de Fichte, tampouco a intuição intelectual absoluta de Schelling; ambas, a reflexão e a intuição intelectual, devem ser apenas momentos da refutação, mas não o seu fim e resultado, que seria apenas o conceito.

2. Teria sido certamente necessário que o presente texto fosse aumentado em larga medida para que pudesse apresentar com maior profundidade boa parte das posições aqui dispostas. Mas uma tal tarefa ultrapassaria o escopo do presente trabalho.

3. G.W.F. HEGEL, Werke in 20 Bänden, Frankfurt a.M.: Suhrkamp, 1970, vol. 6, p. 218. (doravante TW, seguido do volume da edição)

4. As raízes de seu uso já se apresentam, em nossa opinião, no pensamento kantiano pelo menos desde 1762. Cf. o texto pré-crítico Versuch den Begriff der negativen Größen in die Weltweisheit einzuführen, e o uso do conceito 'Gegenverhältnis'.

5. Essas três totalidades são uma e mesma reflexão, mas enquanto uma diferença completamente translúcida, isto é, o conceito.

6. Hegel pretende, com a crítica à filosofia da Reflexão de Fichte e à filosofia da Identidade de Schelling, e com a opinião de que a ciência se fundamenta na apresentação do conceito apenas, superar a inacessibilidade da qual os escritos de Fichte e Schelling eram acusados: "embora a primeira aparição de um mundo novo seja somente o todo envolto em sua simplicidade, ou seu fundamento universal, no entanto, para a consciência, a riqueza do ser-aí anterior ainda está presente na rememoração. Na figura que acaba de aparecer, a consciência sente a falta da expansão e da particularização do conteúdo; ainda mais: falta-lhe aquele aprimoramento da forma, mediante o qual as diferenças são determinadas com segurança e ordenadas segundo suas sólidas relações. Sem tal aprimoramento, carece a ciência da inteligibilidade universal; e tem a aparência de ser uma posse esotérica de uns tantos indivíduos. Digo "posse esotérica" porque só é dada no seu conceito, ou só no seu interior; e "uns tantos indivíduos", pois seu aparecimento, sem difusão, torna singular seu ser-aí. Só o que é perfeitamente determinado é ao mesmo tempo exotérico, conceitual, capaz de ser ensinado a todos e de ser a propriedade de todos. A forma inteligível da ciência é o caminho para ela, a todos aberto e igual para todos. A justa exigência da consciência, que aborda a ciência, é chegar por meio do entendimento ao saber racional: já que o entendimento é o pensar, é o puro Eu em geral. O inteligível é o que já é conhecido, o que é comum à ciência e à consciência não-científica, a qual pode através dele imediatamente adentrar a ciência." (Phänomenologie des Geistes, TW3, p. 19; a partir da tradução de P. Meneses: Fenomenologia do Espírito, Petrópolis: Vozes, 2002, p. 32)

7. I. KANT, Versuch den Begriff der negativen Größen in die Weltweisheit einzuführen (Kant, Werke, II, p. 777 sq.)

8. J. G. FICHTE, Fundamentos da Doutrina da Ciência Completa, trad. D. Ferrer, Ed. Colibri, Lisboa, 1997. p. 39.

9. W. V. CSECH, Die Raumlehre Johann Gottlieb Fichtes, mit Berücksichtigung philosophiegeschichtlicher Konstellationen. Bern: Peter Lang, 1999.

10. Em 'CSECH, op.cit. p. 71' encontramos a seguinte citação de Fichte: “a geometria tem necessariamente, de acordo com a sua essência e sua determinação, apenas evidência factual a respeito de seu princípio; pois ela é um fragmento da região do saber; não pode perceber, enquanto fragmento, sua própria possibilidade dentro desse reino, mas descobre essa sua possibilidade apenas factualmente. Na medida que digo isso e que quero prová-lo, preciso estar acima e além dela mesma: na filosofia. (GA II/9, 125, 3-8)". Quanto a isso, seria muito mais possível traçar uma analogia entre a maneira kantiana de hierarquização das ciências e o modelo aristotélico da relação entre a ciência do ente enquanto ente e as ciências subordinadas, do que a 
maneira platônica. Não se trata, pretensamente para Aristóteles e Kant, de negar a metodologia das ciências subordinadas, ou a verdade de seus princípios, mas deve tratar a filosofia apenas de prover a reflexividade a respeito de seu próprio posicionamento no todo do saber, reflexividade essa que não caberia às ciências subordinadas, cujo princípio e procedimento deve, por si e para si, "fazer fé", i.e. bastar por si mesmos. (Cf. PORCHAT, Ciência e Dialética em Aristóteles, São Paulo: Ed. Unesp, 2001, pp. 255-259.) O que está em questão a respeito disso seria a diferença entre a doutrina aristotélica e a platônica referente ao papel da dialética frente às ciências particulares, a dialética platônica negando os princípios dessas ciências, ao passo que a dialética aristotélica não poderia ser dita elevar-se a tanto.

11. Csech, op.cit. p. 72.

12. Csech, op.cit., p. 69: "alcançar e legitimamente captar as limitações particulares, isto separa a geometria da doutrina da ciência. A tarefa da doutrina da ciência condiz muito mais com o tomar em consideração a limitabilidade do limitável enquanto tal. Com isso, mostra-se, entretanto, também uma analogia metodológica. A doutrina da ciência completa exaure o sistema total das limitações possíveis da razão, e ilumina com isso num dado local também a forma específica da limitabilidade do espaço, certamente sem diminuir os resultados da geometria. "Como, p. ex., a geometria abraça todo o sistema de nossas limitações do espaço, então ela abraça o sistema total da razão." (GA I/7, 160, 9-11)".

\section{RESUMOS}

This text is an attempt to present some of the questions dealing with Hegel's critique of the intellectual intuition and of the form of the mathematical deduction, which had lead us to approach a few aspects of the philosophies of Kant and Fichte. We have tried, departing from Hegel's Science of Logic, to observe the possible mathematical inspiration for what Hegel names Reflexionsphilosophie (Kant, Jacobi, Fichte), and, with it, to observe how, in Hegel's opinion, only a severe criticism of the mathematical procedure would be able to change reflection up into effective negation.

\section{ÍNDICE}

Keywords: reflection, negativity, Hegel, Kant, Fichte, method

\section{AUTOR}

\section{FÁBIO MASCARENHAS NOLASCO}

Universidade Estadual de Campinas 